\title{
Effects of Stimulant Medication, Incentives, and Event Rate on Reaction Time Variability in Children With ADHD
}

\author{
Jeffery N Epstein*,', William B Brinkman', Tanya Froehlich', Joshua M Langberg', Megan E Narad', \\ Tanya N Antonini', Keri Shiels', John O Simon' and Mekibib Altaye' \\ 'Division of Behavioral Medicine and Clinical Psychology, Cincinnati Children's Hospital Medical Center, Cincinnati, OH, USA
}

\begin{abstract}
This study examined the effects of methylphenidate $(\mathrm{MPH})$ on reaction time (RT) variability in children with attention deficit hyperactivity disorder (ADHD). Using a broad battery of computerized tasks, and both conventional and ex-Gaussian indicators of RT variability, in addition to within-task manipulations of incentive and event rate (ER), this study comprehensively examined the breadth, specificity, and possible moderators of effects of MPH on RT variability. A total of 93 children with ADHD completed a 4-week within-subject, randomized, double-blind, placebo-controlled crossover trial of MPH to identify an optimal dosage. Children were then randomly assigned to receive either their optimal MPH dose or placebo after which they completed five neuropsychological tasks, each allowing trial-by-trial assessment of RTs. Stimulant effects on RT variability were observed on both measures of the total RT distribution (ie, coefficient of variation) as well as on an ex-Gaussian measure examining the exponential portion of the RT distribution (ie, $\tau$ ). There was minimal, if any, effect of MPH on performance accuracy or RT speed. Within-task incentive and ER manipulations did not appreciably affect stimulant effects across the tasks. The pattern of significant and pervasive effects of MPH on RT variability, and few effects of MPH on accuracy and RT speed suggest that MPH primarily affects RT variability. Given the magnitude and breadth of effects of MPH on RT variability as well as the apparent specificity of these effects of $\mathrm{MPH}$ on RT variability indicators, future research should focus on neurophysiological correlates of effects of $\mathrm{MPH}$ on RT variability in an effort to better define MPH pharmacodynamics.

Neuropsychopharmacology (201 I) 36, 1060-1072; doi:10.1038/npp.2010.243; published online 19 January 20II
\end{abstract}

Keywords: ADHD; reaction time; stimulants; variability; incentive; event rate

\section{INTRODUCTION}

Across nearly every type of neuropsychological task (eg, response inhibition, working memory, attention) that measures trial-by-trial reaction times (RTs), children with attention deficit hyperactivity disorder (ADHD) have been shown to be significantly more variable in their RT than typically developing controls (Castellanos et al, 2005; de Zeeuw et al, 2008; Hervey et al, 2006; Johnson et al, 2007; Klein et al, 2006; Kuntsi et al, 2001; Leth-Steensen et al, 2000; Mullins et al, 2005; Rubia et al, 2001; Schachar et al, 1995; Shanahan et al, 2008; Teicher et al, 2004; Vaurio et al, 2009). With stimulant medication (eg, methylphenidate (MPH)), RT variability attenuates (Boonstra et al, 2005; Castellanos et al, 2005; Epstein et al, 2006; Fitzpatrick et al, 1992; Rosa-Neto et al, 2005; Spencer et al, 2009; Tannock

*Correspondence: Professor JN Epstein, Division of Behavioral Medicine and Clinical Psychology, Cincinnati Children's Hospital Medical Center, 3333 Burnet Avenue, ML 10006, Cincinnati, OH 45229, USA, Tel: + | 513736 |809, Fax: + | 5136360755 ,

E-mail: jeff.epstein@cchmc.org

Received I5 July 2010; revised I November 2010; accepted I5 December 2010 et al, 1995; Teicher et al, 2004) and may even normalize (Epstein et al, 2006), although some studies have failed to replicate this effect (Johnson et al, 2008; Tucha et al, 2006).

Given the magnitude of the effects of MPH on RT variability, further examination of this relationship may help to elucidate mechanisms of action of MPH on cognitive function. The effects of MPH on RT variability can be better understood using both advanced statistics and methodologies. Statistically, the most commonly used indicator of $\mathrm{RT}$ variability in the literature has been the SD of RTs (Boonstra et al, 2005; Fitzpatrick et al, 1992; Rosa-Neto et al, 2005; Tannock et al, 1995; Teicher et al, 2004). Recently, ex-Gaussian indicators (eg, $\tau$ ) have been used to describe RT variability and, demonstrate that RT variability among children with ADHD is caused by increased positive skew in the RT distribution (Hervey et al, 2006; LethSteensen et al, 2000; Vaurio et al, 2009). Further, research has demonstrated that this positive skew is attenuated by stimulant medication (Epstein et al, 2006; Spencer et al, 2009).

Methodologically, studies examining the effects of MPH on RT variability have begun to examine potential interactions between effects of MPH and task characteristics 
(ie, incentive, event rate (ER)). Although beneficial effects of either MPH or incentive on RTs have been reported, there does not appear to be a synergistic effect of combining MPH and incentive (Groom et al, 2010). Also, although it is well documented that slowing ER increases RT variability in children with ADHD (Hervey et al, 2006; Uebel et al, 2010; van der Meere et al, 2005), the effects of slower ER on RT variability are attenuated when children are on medication (Boonstra et al, 2005; Epstein et al, 2006).

A limitation of research examining the effects of MPH on RT variability to date is that studies have used a wide variety of task paradigms to assess $\mathrm{RT}$ variability leading to conflicting results. Tasks range from simple choice discrimination tasks (Spencer et al, 2009) to more complex response inhibition tasks such as Go/No-Go (GNG) task (Boonstra et al, 2005; Epstein et al, 2006; Groom et al, 2010) and Stop Signal task (SST) (Boonstra et al, 2005). Some paradigms (eg, SST (Boonstra et al, 2005); and Sustained Attention to Response Test (Johnson et al, 2008)) have not shown effects of MPH on RT variability. Inclusion of multiple task paradigms, spanning multiple cognitive processes in one study, may help in understanding whether effects of MPH on RT variability are limited to specific cognitive processes or possibly to task complexity. Samples have also primarily been non-medication naïve (see Johnson et al, 2008 for exception), which introduces potential effects of chronic exposure to medication on brain structure and function (see review by Andersen, 2005). With regard to the medication manipulation, some studies have not used randomization to assign participants to medication conditions (Epstein et al, 2006), which introduces selection bias. Other studies have used randomization but have not titrated to the optimal dosage for each child (Krusch et al, 1996; Spencer et al, 2009; see Boonstra et al, 2005 for exception), which might have resulted in suboptimal dosages for children. These multiple limitations in the existing research have hindered our understanding of the effects of medication on RT variability in children with ADHD.

The present study is a comprehensive study of effects of MPH on RT variability in children with ADHD, which addresses many of these limitations. All participants completed a within-subject, randomized, double-blind, placebo-controlled trial of MPH at three dosages, so that each participant's dosage could be optimally titrated. Children were then randomized to either receive their optimal dosage or placebo after which they were tested on a range of cognitive tasks that included within-task manipulations of ER and incentive so that the breadth of effects of MPH on RT variability could be examined and so that interactions between MPH effects and incentive and ER could be assessed.

\section{PATIENTS AND METHODS}

\section{Participants}

The study included 93 medication-naïve children (aged $7-11$; mean $=8.11, \mathrm{SD}=1.22$ ) who met diagnostic criteria for ADHD (48 ADHD-I; 45 ADHD-C). Children were primarily boys $(n=68)$. Approximately, $75 \%$ of the sample was of Caucasian race, 22\% was African American, and 3\% was of other racial origin. Children with a full-scale IQ below 80, as estimated by the Wechsler Abbreviated Scale of Intelligence (WASI), were excluded from participation in the study. The mean IQ of participating children was 105.58 $(\mathrm{SD}=12.94)$. Children with standardized achievement scores below 80 on the Wechsler Individual Achievement Test, Second Edition (WIAT-II) Reading or Numerical Operations subtests were also excluded from the study to rule out children with possible learning disorders. Children were also excluded from the study if their medical history suggested organic brain injury (eg, traumatic brain injury, epilepsy, history of cerebral infarction, etc).

Children were recruited through multiple community and clinical sources, including schools and local practitioners, to participate in a study of the effects of medication on cognitive functioning. Diagnostic status was determined using methodology similar to that used by the Multimodal Treatment Study of ADHD (MTA Cooperative Group, 1999). Specifically, children were considered to have met criteria for a symptom domain (ie, inattention and/or hyperactivity/ impulsivity) if the parent on the Diagnostic Interview Schedule for Children-Parent Report (DISC-P; Shaffer $e t$ al, 2000), and the teacher on the Vanderbilt ADHD Teacher Rating Scale (VARS; Wolraich et al, 1998) reported six nonoverlapping symptoms in a symptom domain, and both parent and teacher reported at least four symptoms in that domain. Mean symptom scores on the parent (inattention mean $=7.63, \mathrm{SD}=1.83$; hyperactivity-impulsivity mean $=$ 5.68, $\mathrm{SD}=2.80$ ) and teacher VARS (inattention mean $=7.19, \mathrm{SD}=2.03$; hyperactivity-impulsivity mean $=$ $4.71, \mathrm{SD}=3.11$ ) indicated inattention symptom counts consistent with DSM-IV criteria. Mean hyperactivity/ impulsivity symptom counts were attenuated below DSMIV thresholds because of the significant numbers of children with ADHD-inattentive type in our sample. Children were also required to meet DSM-IV criteria for age of onset, pervasiveness, and impairment, as reported by the parent on the DISC-P. The DISC-P assessed for a range of comorbid disorders in our sample, including oppositional defiant disorder $(n=34)$, conduct disorder $(n=4)$, anxiety disorders $(n=31)$, and mood disorders $(n=2)$. To participate, children were required to be medication-naïve with no previous psychoactive medication treatment.

\section{Measures}

Participants completed five computer-based neuropsychological tasks (Choice Discrimination, Child Attentional Network, GNG, SST, and N-back tasks) that assessed a range of neuropsychological domains (eg, response inhibition, working memory, and attention). Tasks were programmed using E-prime 1.2, and were administered on a desktop computer with a $17^{\prime \prime}$ monitor and response pad (Cedrus RB-834). Incentive was manipulated within tasks for all participants, such that participants were able to earn points for performance on half of the trials of each task. The incentive condition was blocked so that the child either received incentives on the first half of each task or on the second half of the task. For each task, participants were explicitly informed on which half of the trials they were able to earn points for accurate responses and lose points for errors through both verbal ('you will earn points for this 
section') and visual prompts (ie, a green border appeared around the screen on incentive trials). At the end of each task, the number of points earned during the task was reported to the child. Participants were informed that they would be able to use the points to 'purchase' incentives (ie, toys, games, school supplies, etc) following completion of all tasks.

Three different ERs were used within each task. Stimulus presentation was held constant at $500 \mathrm{~ms}$ for each task. Although some of the tasks had interstimulus events, with varying events (eg, warning cues during the Attentional Network Task (ANT)), the interstimulus intervals (ISI) were held constant across tasks, so that there was 1,3 , or $5 \mathrm{~s}$ time between stimulus presentations. Hence, the three different ERs were 1.5, 3.5, and $5.5 \mathrm{~s}$. Each task was divided into six continuous 'blocks' of trials, with ER varying across blocks. The three ER blocks were randomized within tasks to ensure that all three ERs occurred in a random order during the first half, or first three blocks, and again in a different random order during the the second half, or final three blocks. Both the ER and incentive condition order was counterbalanced across subjects. Excluding the practice trials, each task took $21 \mathrm{~min}$ to complete except for the Child ANT task, which took $14 \mathrm{~min} 48 \mathrm{~s}$ to complete.

Choice discrimination task (Choice). Participants observed a continuous stream of individually presented stimuli (ie, circles and squares), and were asked to push a specific key for circle and another key for square. A target stimulus was presented, followed by presentation of a fixation cross for the duration of the ISI. Following a 20-trial practice block, participants were presented with six blocks of 60 trials apiece, for a total of 360 trials. Each block contained an equal proportion of circles and squares, and the order of stimulus presentation within blocks was randomly determined. ER was varied across blocks. During incentive conditions, participants were notified that they would receive one point for each correct response and lose one point for each incorrect response.

Child attentional network task (CANT). Participants were presented with a target stimulus (a fish) either individually or in the center of a horizontal row of five distractor stimuli (identical fish) (Rueda et al, 2004). The row of fish either appeared on the upper portion of the screen $(50 \%)$ or on the lower portion of the screen (50\%). The task included congruent trials (target facing the same direction as distractors), incongruent trials (target facing the opposite direction as distractors), and neutral trials (target presented by itself). Within each condition, participants were instructed to indicate the direction of the target stimulus. Before each trial, participants were provided with one of four target cues: (1) a central cue (ie, in the center of the screen), (2) a double cue (ie, above and below the center of the screen), (3) a spatial cue (ie, in the location in which the target will appear), or (4) no cue. See Rueda et al (2004) for a more comprehensive description and depiction of the task. Each cue was maintained for $150 \mathrm{~ms}$, followed by a $450 \mathrm{~ms}$ presentation of a fixation cross, followed by a $500 \mathrm{~ms}$ stimulus presentation, and then followed by presentation of a fixation cross for the duration of the ISI. Following a 20-trial practice block, participants were presented with six blocks of 48 trials apiece for a total of 288 trials. Equivalent proportions of each target condition (33\% congruent, $33 \%$ incongruent, $33 \%$ neutral) and cue condition (25\% central cue, $25 \%$ double cue, $25 \%$ spatial cue, $25 \%$ no cue) were present within each block, with cues distributed equally among the targets. ER was varied across blocks. During the incentive condition, participants were instructed that they would receive a point for each correct response and lose a point for each incorrect response.

Go/No-Go task (GNG). The GNG task required participants to respond (ie, pressing the spacebar) to a variety of nontarget stimuli (ie, individually presented letters on a screen), inhibit their response to a specific target stimuli (the letter ' $\mathrm{X}$ '). Target and non-target stimuli appeared individually on the computer screen for $500 \mathrm{~ms}$ followed by presentation of a fixation cross for the duration of the ISI. Participants were initially presented with 20 practice stimuli, and then completed 360 trials organized in six continuously presented blocks of 60 trials with ER varying across blocks. A ratio of $10 \%$ target stimuli and $90 \%$ non-target stimuli was maintained within each block. During the incentive condition, participants were informed that they would receive one point for each accurate response including correct inhibitions to the letter ' $\mathrm{X}$ ' and lose five points for each commission error (ie, pressing the response key in response to the letter ' $\mathrm{X}$ ').

Stop-signal task (SST). A fixation cross was presented in the center of a computer screen for $500 \mathrm{~ms}$ followed by a $500 \mathrm{~ms}$ presentation of a target stimulus (an airplane), facing to either left or right. Participants were provided with a response pad, and asked to press the button that corresponded to the direction toward which the target stimulus was facing. However, an auditory 'stop-signal' ( $1000 \mathrm{~Hz}$ tone) was presented on $25 \%$ of trials within each block, which required participants to inhibit their response to the visual stimulus (stop trials). The delay between presentation of the target stimulus and the tone began at $250 \mathrm{~ms}$ and varied according to the participant's performance. Successful inhibition resulted in increases of $50 \mathrm{~ms}$ and unsuccessful inhibition resulted in decreases of $50 \mathrm{~ms}$, so that the rate of inhibition was controlled to approximate $50 \%$. The delay was reset to $250 \mathrm{~ms}$ at the beginning of each reward block. Following three practice blocks of 20 trials each (one block without stop-signal, two with stop-signal), participants completed six blocks consisting of 60 trials apiece for a total of 360 trials. ER was varied across blocks. During incentive conditions, children were instructed that they would earn one point for each successful response on non-stop trials and lose four points for each incorrect response on non-stop trials. Reaction time was recorded only for non-stop trials.

$N$-back task (N-back). The present study used a one-back design, in which participants were instructed to push one button if the currently presented letter was identical to the previous (one-back), and another button if the letter was different from the previous one. Letters were presented on the screen continuously for $500 \mathrm{~ms}$ followed by a fixation cross for the duration of the ISI. Following a 20-trial practice block, participants were presented with six blocks 
of 60 trials apiece, for a total of 360 trials. The target condition (identical letter as one-back trial) was present in $30 \%$ of the trials within each block, and the three ER conditions were varied across the six blocks. During the incentive condition, participants were instructed that they would earn one point for each stimulus they correctly identified and lose one point for every incorrect response.

\section{Medication Titration Trial}

Participants completed a 4-week within-subject, randomized, double-blind, placebo-controlled crossover trial of long-acting OROS MPH (Concerta), including three active dosage weeks $(18,27$, and $36 \mathrm{mg}$ for children $<25 \mathrm{~kg} ; 18,36$ or $54 \mathrm{mg}$ for children $\geqslant 25 \mathrm{~kg}$ ) and 1 week of placebo. Study medication consisted of identical capsules filled with either an inert white powder (placebo) or the prescribed dose of Concerta overencapsulated to preserve the double blind. At the end of each week, teachers and parents completed the Vanderbilt ADHD Rating Scales (Wolraich et al, 1998) and Pittsburgh Side-Effects Rating Scale (Pelham, 1993). The study physician also met with participants and families at the end of each week of the medication trial and completed a Clinical Global Impression-Improvement (CGI-I) to assess response to medication.

At the end of the medication titration trial, the treating physician (WB) and another physician (TF) blindly reviewed graphs portraying parent and teacher ratings of symptoms and side effects, and the study physician's CGI-I rating for each of the 4 weeks. On the basis of this information, they each selected an optimal week on the basis of the balance between effectiveness and side effects. See Table 1. Rater agreement on participant optimal week was good (84\% agreement). For cases in which there was disagreement between physicians, the two physicians discussed the case and came to a consensus rating (Greenhill et al, 2001). For cases in which multiple weeks appeared equal in symptom remediation and side-effect profile, the week with the lowest medication dosage was designated as the optimal dose.

Table I Children's Optimal Dosages as Determined Through Titration Trial by Randomized Condition During Neuropsychological Testing

\begin{tabular}{lcr}
\hline $\begin{array}{l}\text { Titration trial optimal } \\
\text { dosages }\end{array}$ & \multicolumn{2}{c}{ Randomized condition } \\
\cline { 2 - 3 } & $\begin{array}{c}\text { Optimal dose } \mathbf{N} \\
(\mathbf{m g} / \mathbf{k g *})\end{array}$ & $\begin{array}{c}\text { Placebo } \mathbf{~} \\
\mathbf{( m g / k g * )}\end{array}$ \\
\hline Placebo & $9(\mathrm{~N} / \mathrm{A})$ & $13(\mathrm{~N} / \mathrm{A})$ \\
Low dose & $12(0.52)$ & $8(0.52)$ \\
Medium dose & $14(1.09)$ & $15(1.10)$ \\
High dose & $12(1.72)$ & $10(1.68)$ \\
Average $\mathrm{mg} / \mathrm{kg}$ & $1.13 \mathrm{mg} / \mathrm{kg}$ & $1.13 \mathrm{mg} / \mathrm{kg}$ \\
\hline
\end{tabular}

Abbreviations: $\mathrm{mg}$, milligrams of methylphenidate; $\mathrm{kg}$, kilograms.

* $\mathrm{mg} / \mathrm{kg}$ computed using child's weight (in $\mathrm{kg}$ ) before medication trial divided by the number of $\mathrm{mg}$ of methylphenidate received during week of optimal dosage.

\section{Procedures}

Participants and their parents completed an initial screening visit and two neuropsychological assessment visits during which they completed the aforementioned neuropsychological testing. During the screening visit, parents were administered the DISC-P interview, and children were administered the WASI and WIAT-II. Results of the initial neuropsychological testing are published elsewhere (Epstein et $a l$, in press). Participants then completed the medication titration trial. Participants were then randomly assigned to receive either a placebo or the optimal dosage from the medication titration trial. See Table 1. Children took either placebo or optimal dosage for a week. Medication was delivered to children at home by parents. During that week, children participated in 2 days of neuropsychological testing using the aforementioned battery. All testing occurred between 1 to $4 \mathrm{~h}$ after medication ingestion, as reported by parents. Tasks were administered in a counterbalanced fashion.

\section{Statistical Analyses}

For any task, if the percentage of omission errors exceeded $50 \%$, performance on that task was omitted from all analyses. Children whose task data was omitted did not differ from children who were included in the analyses on the following variables: age, sex, race, ODD, conduct disorder, anxiety disorder, mood disorder, or parent- or teacher-rated ADHD symptom scores. Children with omitted data did have lower full-scale WASI scores than children included in the analyses $(t(89)=2.62, p<0.05)$.

Summary statistics were created as follows. For computation of summary statistics involving RTs, only RTs on successful trials were used. Also, all RTs less than $100 \mathrm{~ms}$ were excluded as the non-decision portion of simple RT is approximately $100 \mathrm{~ms}$ (Luce, 1986). Mean RT for each participant was computed by averaging RTs on correct response trials. RT standard deviation (RT SD) was derived by computing the SD of each individual's RTs. Coefficient of variation (CV) for each participant was computed by dividing the SD of the RTs by the mean RT; this provides a measure of RT variability, controlling for RT speed. Percent accuracy was calculated by computing the number of correct responses divided by the number of trials. RTSYS 1.0 (Heathcote, 1996) was used to provide ex-Gaussian estimates. The ex-Gaussian distribution has three parameters. $\mathrm{Mu}(\mu)$ and sigma $(\sigma)$ represent the mean $(\mathrm{mu})$ and SD $(\sigma)$ of the normal component of the distribution, respectively. Tau represents the exponential component of the distribution or positive skew. For each of the five cognitive tasks, all indicators were calculated within each subject, and were stratified by the three ER conditions (1.5, 3.5 , and $5.5 \mathrm{~s}$ ) and two incentive conditions (incentive and no incentive) for a total of six summary variables. Owing to lack of fit between the data and the ex-Gaussian function, a percentage of ex-Gaussian indicators were unable to be computed for each task (Choice $=2.9 \%$; $\mathrm{ANT}=5.2 \%$; $\mathrm{GNG}=8.5 \%$; Stop Signal $=10.6 \%$; and $\mathrm{N}$-back $=8.7 \%$ ). Children with a full complement of data were compared with those with missing ex-Gaussian indicators on age, sex, race, ODD, conduct disorder, anxiety disorder, mood 
disorder, or parent- or teacher-rated ADHD symptom domain scores. For one of these comparisons, there was a difference between subgroups, indicating that children with missing data had higher parent-rated inattention scores than children with a full complement of data $(t=2.58$, $p<0.05)$.

Correlations between the seven indicators across tasks were computed using Pearson's correlations. In addition, to estimate test-retest reliability for our indicators, correlations were computed using pre-and post-titration trial (lag time $=5-6$ weeks) neuropsychological testing for the 46 ADHD participants who were randomly assigned to the placebo group. Both inter-indicator correlations and testretest reliabilities were estimated at the level of analysis using estimates from each incentive $\times$ reward condition.

Linear mixed models (ie, SAS PROC MIXED) were used to test for medication effects (MPH or placebo) and withinsubject effects (ER and incentive), as well as all interactions including medication effect (ie, $\mathrm{MPH} \times$ incentive, $\mathrm{MPH} \times \mathrm{ER}$, and $\mathrm{MPH}$ two incentive $\times \mathrm{ER}$ ) for each of the seven summary measures (RT mean, $\mathrm{RT} \mathrm{SD}, \mathrm{CV}, \mu, \sigma$, and $\tau$, and percent accuracy). These models were run separately for each of the five cognitive tasks. Linear mixed models account for the expected correlation among data points collected from the same individual. The three-way interaction between $\mathrm{MPH}, \mathrm{ER}$, and incentive was not significant in all models, and thus was subsequently removed as a modeled interaction from all models. The above analyses were considered as our primary analyses. To control for multiple testing (ie, multiple outcomes for each task) in our primary analyses, a false discovery rate correction (FDR) was used (Benjamini and Hochberg 1995). All p-values presented for these primary analyses are the FDR-corrected $p$-values.

As two of the tasks have unique variables, not captured by RT and accuracy alone, we also conducted linear mixed models with these variables to examine main effects of $\mathrm{MPH}, \mathrm{ER}$, and incentive and their interactions. These were considered secondary analyses. On the SST, Stop Signal RT (SSRT) was computed by subtracting the average stop signal delay from the mean hit RT (Logan, 1994). On the ANT task, alerting, orienting, and conflict variables were computed as follows: alerting score $=$ median $\mathrm{RT}$ for no cue condition $-\vartheta$ median RT for double cue condition; orienting scor$\mathrm{e}=$ median $\mathrm{RT}$ for central cue condition - median RT for spatial cue condition; and conflict score $=$ median RT for incongruent cue condition-median RT for congruent cue condition (Rueda et al, 2004). Higher scores on each of these variables indicated increased benefit from alerting cues (alerting score), orienting cues (orienting score), and congruent $v s$ incongruent cues (conflict score), respectively. For these secondary analyses, a $p$-value of 0.05 was used to test for significance.

\section{RESULTS}

\section{Behavioral Outcomes}

Parental ratings of ADHD behavior showed a significant improvement during the optimal dose week (Mean Total Symptom Score $(\mathrm{TSS})=19.16, \quad \mathrm{SD}=10.09) \quad$ compared with the placebo week (Mean $\mathrm{TSS}=28.26, \mathrm{SD}=11.12$; $t(92)=7.86, p<0.0001)$. Likewise, teacher ratings during the optimal dose week (Mean TSS $=17.15, \mathrm{SD}=10.87$ ) were significantly better than those during the placebo week (Mean TSS $=26.67, \mathrm{SD}=12.04 ; t(79)=7.74, p<0.0001$ ). Effect sizes (Cohen's $d$ ) for these behavioral effects of medication were 0.82 and 0.87 for parent and teacher ratings, respectively.

\section{Neuropsychological Outcomes}

Seven separate indicators (RT mean, RT SD, CV, $\mu, \sigma, \tau$, and percent accuracy) were examined for each task. The mean and range of correlations between indicators at the level of analyses (ie, using data from each reward $\times$ ER condition) are presented in Table 2. Mean correlations between the three indicators of RT variability (RT SD, CV, and $\tau$ ) were high (range $=0.51-0.75$ ). Correlations between mean RT and percent accuracy (ie, accuracy-speed trade-off) were low (mean $=-0.05)$. The mean test-retest reliabilities were high for RT mean $(r=0.72)$, moderate for RT SD $(r=0.52)$, $\tau(r=0.49)$, mu $(r=0.48)$, and percent accuracy $(r=0.40)$, and low for CV $(r=0.27)$ and $\sigma(0.21)$. See Table 2 . Reliabilities did vary across tasks with a pattern of higher reliability estimates for the Choice task and the lowest reliabilities for estimates on the $\mathrm{N}$-back task.

Reaction time. The main effect of MPH was nonsignificant across all five tasks. The main effect of ER was significant across all tasks (all $p$-values $<0.0001$ ) indicating faster $\mathrm{RT}$ with faster ER. The main effect of incentive was significant only for the GNG task with faster RTs during incentive conditions $(\mathrm{F}(1,84)=12.92, p<0.01)$. On the GNG task, there was also an interaction of $\mathrm{MPH} \times$ incentive $(\mathrm{F}(1$, $84)=7.18, p<0.05)$. The group receiving $\mathrm{MPH}$ performed similarly across the incentive and no-incentive conditions, whereas the placebo group showed a pattern of faster RTs in the incentive condition and slowed RTs in the no-incentive condition. No other interaction effects were present on the GNG or any of the other tasks. See Table 3.

Standard deviation. RT variability, as measured by RT SD, was lower in children taking $\mathrm{MPH}$ than in children taking placebo on the ANT task $(\mathrm{F}(1,84)=17.23, p<0.001)$ and the GNG task $(\mathrm{F}(1,84)=11.44, p<0.01)$. There was also a main effect of incentive on these same tasks: ANT task $(\mathrm{F}(1$, $84)=7.08, p<0.05)$; GNG task $(\mathrm{F}(1,84)=14.72, p<0.01)$. Children had lower RT SD during incentive conditions compared with non-incentive conditions on these two tasks. There were main effects of ER across all five tasks, as children demonstrated lower RT SD as ER became faster (all $p s<0.0001)$. Finally, there was a MPH $\times$ ER interaction on the ANT task $(\mathrm{F}(2,84)=7.56, p<0.01)$. Children across $\mathrm{MPH}$ and placebo conditions had similar RT SDs in the fast ER condition. However, children in the placebo condition showed substantially more variability as indicated by RT SD at slower ERs compared with the increases observed for children in the MPH condition. See Table 3.

Coefficient of variation. RT variability, as measured by CV, was lower in children receiving MPH than children receiving placebo (ie, main effect of $\mathrm{MPH}$ ) on the ANT 
Table 2 Mean (and range) Correlations Between Seven Primary Performance Indicators and Mean (and Range) Test-Retest Correlations* Across the Five Neuropsychological Tasks

\begin{tabular}{|c|c|c|c|c|c|c|c|}
\hline Variable & RT mean & RT SD & CV & Mu & Sigma & Tau & $\begin{array}{l}\text { Percent } \\
\text { accuracy }\end{array}$ \\
\hline RT mean & $0.72(0.64-0.8 I)$ & & & & & & \\
\hline $\begin{array}{l}\text { Coefficient } \\
\text { of variation }\end{array}$ & $0.22(-0.09-0.43)$ & $0.73(0.60-0.84)$ & $0.27(0.13-0.38)$ & & & & \\
\hline $\mathrm{Mu}$ & $0.72(0.5 \mid-0.90)$ & $0.42(0.31-0.52)$ & $-0.04(-0.16-0.12)$ & $0.48(0.39-0.62)$ & & & \\
\hline Tau & $0.63(0.31-0.77)$ & $0.75(0.48-0.93)$ & $0.5 \mathrm{I}(0.14-0.75)$ & $0.17(-0.14-0.33)$ & $0.20(0.02-0.27)$ & $0.49(0.10-0.68)$ & \\
\hline $\begin{array}{l}\text { Percent } \\
\text { accuracy }\end{array}$ & $-0.05(-0.35-0.14)$ & $-0.22(-0.51--0.05)$ & $-0.33(-0.54--0.13)$ & $-0.02(-0.30-0.11)$ & $-0.24(-0.41--0.09)$ & $-0.11(-0.38-0.07)$ & $0.40(0.29-0.54)$ \\
\hline
\end{tabular}

Abbreviations: RT, reaction time; SD, standard deviation.

*Test-retest correlations computed using pre-and post-titration trials testing for 46 children assigned to the placebo group. Presented on diagonal.

task $(\mathrm{F}(1,84)=13.91, \quad p<0.001), \quad \mathrm{GNG}$ task $(\mathrm{F}(1$, $84)=29.97, p<0.0001)$, and $\operatorname{SST}(\mathrm{F}(1,88)=6.11, p<0.05)$. On the Choice Discrimination, ANT, GNG, and SST tasks, there was a significant effect of ER, indicating less variability in RT with faster ERs (all $p$-values $<0.05)$. There was a main effect of incentive for the GNG $(\mathrm{F}(1,84)=8.02, p<0.01)$, with less variable RTs during the incentive condition compared with the no-incentive condition. Finally, there was a significant interaction of $\mathrm{MPH} \times \mathrm{ER}$ on the ANT task $(\mathrm{F}(2,84)=5.82$, $p<0.05)$ and the SST $(\mathrm{F}(2,88)=4.32, p<0.05)$. As reported for the SD outcome, slow ER effects on producing increased RT variability were attenuated for children in the MPH condition. No other main or interaction effects were statistically significant. See Table 3.

\section{Ex-Gaussian Indicators}

$M u(\mu)$. There were no main effects of MPH or incentive across tasks. The main effect of ER was significant across all tasks (all $p s<0.0001$ ), indicating faster RTs in the normal part of the distribution at faster ERs. There was a significant interaction of $\mathrm{MPH} \times$ incentive for the $\operatorname{SST}(\mathrm{F}(1,88)=8.67$, $p<0.05)$ and N-back tasks $(\mathrm{F}(1,75)=6.44, p<0.05)$. Children receiving $\mathrm{MPH}$ had equal values of $\mu$ across incentive and no-incentive conditions, whereas children receiving placebo showed significantly faster $\mu$ values during the incentive condition, both compared with their speed during the no-incentive condition and compared with the MPH group's performance in the incentive condition. See Table 4 .

Sigma $(\sigma)$. There was a significant main effect of MPH on the ANT task $(\mathrm{F}(1,84)=8.97, p<0.05)$, with smaller values of $\sigma$ in the $\mathrm{MPH}$ condition compared with the placebo condition. There were also significant main effects of incentive on the ANT task $(\mathrm{F}(1,84)=13.57, p<0.01)$ and the SST $(F(1,88)=5.97, p<0.05)$, suggesting that incentives did not affect variability in the normal portion of the RT distribution for children receiving $\mathrm{MPH}$, whereas incentives significantly reduced the variability in the normal portion of the RT distribution for children taking placebo. A main effect of ER was evident only on the Choice task $(\mathrm{F}(2$, $85)=4.35, p<0.05)$ with less variability during faster ER conditions. There were significant $\mathrm{MPH} \times$ incentive interactions on the GNG $(\mathrm{F}(1,84)=7.42, p<0.05)$ and SST $(\mathrm{F}(1$, $88)=7.45, p<0.05)$ tasks. Children taking $\mathrm{MPH}$ had similar $\sigma$ values across incentive and no-incentive conditions, whereas children taking placebo had significantly higher values of $\sigma$ when there was no incentive. This pattern was evident across the GNG and SST tasks. No other main effects or interactions were significant. See Table 4.

Tau $(\tau)$. Main effects of MPH were observed on the ANT $(\mathrm{F}(1,84)=19.66, p<0.001), \mathrm{GNG}(\mathrm{F}(1,84)=9.29, p<0.05)$, SST $(F(1,88)=8.87, p<0.05)$, and N-back tasks $(F(1$, $75)=7.91, p<0.05)$. Children taking MPH had significantly less variability in the exponential portion of the RT distribution across these four tasks. No main effect of $\mathrm{MPH}$ was observed on the Choice Discrimination task ( $\mathrm{F}(1$, $85)=0.88, p=0.49$ ). There was no main effect of incentive across tasks. However, there were significant main effects of ER across all tasks (all $p$-values $<0.0001$ ), indicating less variability in the exponential portion of the RT distribution on fast ER trials. The only interaction effect that reached statistical significance was an $\mathrm{MPH} \times \mathrm{ER}$ interaction effect on the ANT task $(\mathrm{F}(2,84)=11.03, p<0.001)$ As seen on the $\mathrm{SD}$ and $\mathrm{CV}$ indicators for this task, children in the placebo group showed considerably more RT variability as ER slowed compared with children in the MPH group. See Table 4.

Accuracy. There were main effects for MPH on the ANT $(\mathrm{F}(1,84)=9.56, p<0.05)$ and $\mathrm{GNG}$ tasks $(\mathrm{F}(1,84)=11.20$, $p<0.01)$, with higher accuracy for children taking $\mathrm{MPH}$ compared with those taking placebo. There were significant main effects of ER on the Choice $(\mathrm{F}(2,85)=37.44$, $p<0.0001)$, ANT $(\mathrm{F}(2,84)=59.22, p<0.0001)$, and SST $(\mathrm{F}(2,89)=37.13, p<0.0001)$ tasks. Accuracy increased as ER slowed. There were also main effects of incentive on the ANT $(\mathrm{F}(1,84)=9.00, p<0.05)$ and $\mathrm{GNG}$ tasks $(\mathrm{F}(1$, $84)=8.39, p<0.05)$. Again, accuracy increased in the presence of incentives. There was an interaction of $\mathrm{MPH} \times$ incentive on the ANT task $(\mathrm{F}(1,84)=8.02$, $p<0.05)$. Accuracy of children in the MPH condition was 
Table 3 Group Means, Standard Errors, and Parametric Test Results for Mean RT, RT SD, CV, and Percent Accuracy Across the Five Tasks

\begin{tabular}{|c|c|c|c|c|c|c|c|c|c|c|c|c|c|c|c|c|c|c|}
\hline \multirow[b]{3}{*}{ Task } & \multicolumn{6}{|c|}{ Medicated } & \multicolumn{6}{|c|}{ Placebo } & \multicolumn{6}{|c|}{ Parametric tests } \\
\hline & \multicolumn{3}{|c|}{ No incentive } & \multicolumn{3}{|c|}{ Incentive } & \multicolumn{3}{|c|}{ No incentive } & \multicolumn{3}{|c|}{ Incentive } & \multirow{2}{*}{ df } & \multirow{2}{*}{$\begin{array}{l}\text { Med } \\
F(E S)\end{array}$} & \multirow{2}{*}{$\begin{array}{l}\text { Incentive } \\
\text { F (ES) }\end{array}$} & \multirow{2}{*}{$\begin{array}{c}\text { ER } \\
F(E S)\end{array}$} & \multirow{2}{*}{$\begin{array}{c}\text { Med } \times \text { Incentive } \\
\text { F }\end{array}$} & \multirow{2}{*}{$\begin{array}{c}\text { Med } \times \text { ER } \\
\qquad F\end{array}$} \\
\hline & $1.5 \mathrm{~s}$ & $3.5 \mathrm{~s}$ & $5.5 \mathrm{~s}$ & $1.5 \mathrm{~s}$ & $3.5 \mathrm{~s}$ & $5.5 \mathrm{~s}$ & $1.5 \mathrm{~s}$ & $3.5 \mathrm{~s}$ & $5.5 \mathrm{~s}$ & $1.5 \mathrm{~s}$ & $3.5 \mathrm{~s}$ & $5.5 \mathrm{~s}$ & & & & & & \\
\hline \multicolumn{19}{|c|}{ Reaction time mean } \\
\hline Choice & $552.5(18.1)$ & $916.8(40.7)$ & I I I $0.9(77.2)$ & $565.4(13.3)$ & $894.3(42.0)$ & $1079.6(78.8)$ & $587.2(17.3)$ & $976.0(40.2)$ & $1102.9(76.5)$ & $589.0(13.2)$ & $969.2(41.6)$ & I | $16.3(78.1)$ & 85 & $0.47(0.15)$ & $0.00(0.00)$ & $121.24 * * *$ & 0.00 & 1.11 \\
\hline ANT & $546.0(15.0)$ & $695.1(30.7)$ & $816.7(41.4)$ & $550.3(12.0)$ & $689.5(30.9)$ & $789.3(41.5)$ & $562.2(14.3)$ & $812.2(28.8)$ & $944.7(39.0)$ & $578.3(11.5)$ & $765.6(27.9)$ & $888.9(38.7)$ & 84 & $5.20(0.49)$ & $0.70(0.13)$ & $88.59 * * *$ & 0.17 & 2.62 \\
\hline GNG & $491.4(24.4)$ & $738.4(41.3)$ & $905.5(49.8)$ & $494.4(15.7)$ & $752.8(38.5)$ & $853.6(49.4)$ & $560.9(24.2)$ & $854.6(42.3)$ & $967.8(51.0)$ & $488.7(16.0)$ & $785.1(39.4)$ & $890.8(50.6)$ & 84 & $1.12(0.23)$ & $12.92 * *(0.56)$ & $105.25 * * *$ & $7.18 *$ & 0.97 \\
\hline SST & $626.1(26.2)$ & $966.6(63.5)$ & | $191.3(89.0)$ & $640.4(21.5)$ & $927.9(59.9)$ & | I $18.3(84.9)$ & $627.9(26.0)$ & $867.8(63.5)$ & $967.6(89.0)$ & $613.3(21.5)$ & $876.4(59.9)$ & $987.6(84.9)$ & 88 & $1.30(0.24)$ & $0.14(0.06)$ & $37.55 * * *$ & 0.32 & 1.69 \\
\hline N-back & $644.5(28.0)$ & $966.1(53.8)$ & $1094.5(65.9)$ & $656.8(23.4)$ & $957.5(50.2)$ & $1081.1(66.2)$ & $684.1(26.8)$ & $971.0(53.1)$ & II52.5 (65.1) & $665.8(23.3)$ & $1040.9(49.5)$ & | $137.4(65.3)$ & 75 & $0.61(0.17)$ & $0.00(0.00)$ & $97.07 * * *$ & 0.06 & 0.25 \\
\hline \multicolumn{19}{|c|}{ Reaction time standard deviation } \\
\hline Choice & $144.7(8.1)$ & $311.6(19.9)$ & $395.5(31.3)$ & $146.9(5.1)$ & $277.3(19.0)$ & $359.3(32.3)$ & $152.0(7.7)$ & $360.7(19.6)$ & $4 \mid 5.4(31.0)$ & $159.3(5.1)$ & 333.7) (18.8) & $439.4(31.9)$ & 85 & $2.22(0.32)$ & $0.32(0.09)$ & $117.92 * * *$ & 1.39 & 1.93 \\
\hline ANT & $115.5(6.7)$ & $210.1(16.3)$ & $273.3(27.7)$ & II $4.7(4.1)$ & $204.8(16.7)$ & $259.7(27.1)$ & $142.6(6.4)$ & 297.1 (15.3) & $406.6(25.5)$ & $123.8(3.9)$ & $281.9(13.3)$ & $357.8(25.0)$ & 84 & $17.23 * * *(0.89)$ & $7.08 * *(0.41)$ & $115.12 * * *$ & 4.49 & $7.56 * *$ \\
\hline GNG & $181.4(15.6)$ & $317.0(28.6)$ & $403.9(43.3)$ & $168.7(10.0)$ & $286.6(26.1)$ & $368.5(39.2)$ & $266.1(15.5)$ & $433.6(29.3)$ & $585.6(44.4)$ & $223.6(10.2)$ & $391.0(26.8)$ & $478.9(40.1)$ & 84 & | I. $.44 * *(0.73)$ & $14.72 * *(0.59)$ & $69.72 * * *$ & 2.80 & 1.53 \\
\hline SST & $219.6(13.0)$ & $292.3(23.0)$ & $404.9(35.3)$ & $212.8(10.5)$ & $271.4(23.1)$ & $335.8(32.8)$ & $217.2(12.8)$ & $337.1(23.0)$ & $388.3(35.3)$ & $212.5(10.5)$ & $306.8(23.1)$ & $382.2(32.8)$ & 88 & $0.32(0.12)$ & $1.88(0.21)$ & $39.68 * * *$ & 0.01 & 2.00 \\
\hline $\mathrm{N}$-back & $215.0(16.7)$ & $341.6(29.9)$ & $402.8(41.2)$ & $196.6(10.7)$ & $318.7(31.8)$ & $347.6(39.5)$ & $226.4(15.6)$ & $345.3(29.5)$ & $441.1(40.7)$ & $219.0(10.6)$ & $373.6(31.4)$ & $405.4(39.0)$ & 75 & $1.40(0.25)$ & $2.28(0.25)$ & $52.99 * * * *$ & 1.25 & 0.36 \\
\hline \multicolumn{19}{|c|}{ Coefficient of variation } \\
\hline Choice & $27.7(1.6)$ & $33.4(1.4)$ & $35.2(1.5)$ & $26.1(1.0)$ & $30.2(1.3)$ & $33.1(1.8)$ & $26.3(1.5)$ & $36.7(1.4)$ & $36.9(1.5)$ & $27.1(1.0)$ & $34.3(1.3)$ & $38.5(1.8)$ & 85 & $3.08(0.38)$ & $5.37(0.36)$ & $36.41 * * * *$ & 2.22 & 2.07 \\
\hline ANT & $21.6(1.4)$ & $29.3(1.5)$ & $31.3(2.0)$ & $21.1(0.8)$ & $29.0(1.7)$ & $31.2(1.8)$ & $25.5(1.4)$ & $35.7(1.5)$ & $41.5(2.0)$ & $21.5(0.8)$ & $35.8(1.6)$ & $37.6(1.7)$ & 84 & $\mid 3.91 * * * 0.80)$ & $4.08(0.31)$ & $100.46 * * *$ & 2.41 & $5.82^{*}$ \\
\hline GNG & $36.6(2.6)$ & $40.5(2.4)$ & $42.1(2.8)$ & $33.6(1.5)$ & $36.4(2.4)$ & $40.7(2.7)$ & $48.2(2.5)$ & $51.0(2.5)$ & $59.8(2.9)$ & $45.3(1.5)$ & $49.1(2.5)$ & $51.7(2.8)$ & 84 & $29.97 * * *(1.17)$ & $8.02 *(0.44)$ & $12.79 * * * *$ & 0.10 & 0.56 \\
\hline SST & $34.6(1.8)$ & $31.4(2.0)$ & $34.9(2.5)$ & $33.4(1.3)$ & $29.3(1.7)$ & $30.8(2.4)$ & $34.6(1.8)$ & $39.6(2.0)$ & $42.3(2.5)$ & 34.1 (1.3) & $35.2(1.7)$ & $39.2(2.4)$ & 88 & $6.11 *(0.53)$ & $5.81(0.36)$ & $4.42 *$ & 0.02 & $4.32 *$ \\
\hline N-back & $31.9(2.5)$ & $34.5(2.3)$ & $35.1(2.3)$ & $30.3(1.5)$ & $32.1(2.2)$ & $30.4(2.8)$ & 34.1 (2.4) & $35.4(2.2)$ & $37.4(2.3)$ & $33.6(1.5)$ & $34.7(2.2)$ & $35.3(2.7)$ & 75 & $1.75(0.28)$ & $3.08(0.29)$ & 1.39 & 0.65 & 0.18 \\
\hline \multicolumn{19}{|c|}{ Percent accuracy } \\
\hline Choice & $74.3(3.4)$ & $85.1(2.6)$ & $89.2(2.0)$ & $77.6(2.4)$ & $88.4(2.0)$ & $88.4(2.4)$ & $71.5(3.3)$ & $81.3(2.6)$ & $84.3(2.0)$ & $72.2(2.4)$ & $82.6(2.0)$ & $82.9(2.4)$ & 85 & $4.24(0.44)$ & $0.51(0.11)$ & $37.44 * * *$ & 0.54 & 0.10 \\
\hline ANT & $75.0(3.2)$ & $88.9(2.4)$ & $90.5(1.9)$ & $80.9(2.0)$ & $89.1(2.0)$ & $89.5(2.0)$ & $63.2(3.1)$ & $78.7(2.4)$ & $82.8(1.9)$ & $71.8(2.0)$ & $86.0(2.0)$ & $86.0(2.0)$ & 84 & $9.56 *(0.66)$ & $9.00 *(0.46)$ & $59.22 * * * *$ & $8.02 *$ & 3.14 \\
\hline GNG & $89.1(2.7)$ & $91.6(2.0)$ & $90.9(2.1)$ & $93.8(1.1)$ & $94.1(1.7)$ & $93.4(2.0)$ & $80.4(2.7)$ & $84.7(2.1)$ & $84.0(2.1)$ & $88.2(1.2)$ & $85.0(1.7)$ & $86.6(2.1)$ & 84 & $11.20 * *(0.71)$ & $8.39 *(0.45)$ & 0.09 & 0.01 & 1.31 \\
\hline SST & $81.6(3.0)$ & $88.1(2.8)$ & $88.3(2.6)$ & $79.8(2.4)$ & $89.1(2.7)$ & $92.3(2.3)$ & $78.4(3.0)$ & $85.2(2.8)$ & $87.7(2.6)$ & $79.0(2.4)$ & $87.9(2.7)$ & $90.5(2.3)$ & 89 & $0.34(0.13)$ & $5.44(0.35)$ & $37.13 * * *$ & 0.02 & 0.06 \\
\hline N-back & $72.0(3.9)$ & $74.7(3.6)$ & $7 \mid .4(3.7)$ & $74.2(3.0)$ & $76.3(3.3)$ & $74.9(3.7)$ & $68.6(3.7)$ & $64.8(3.6)$ & $63.0(3.7)$ & $70.5(3.0)$ & $65.7(3.2)$ & $63.6(3.7)$ & 75 & $3.51(0.40)$ & $1.41(0.19)$ & 2.11 & 0.16 & 3.75 \\
\hline
\end{tabular}

Abbreviations: ANT, Child Attentional Network Test; Choice, Choice Discrimination Task; DV, dependent variable; ER, event rate; ES, effect size (Cohen's ø); GNG, Go/No-Go Task; SST, Stop Signal Task.

${ }^{*} p<0.05, * *{ }_{p}<0.01, * * * * 0<0.001$. 
Table 4 Group Means, Standard Errors, and Parametric Test Results for Ex-Gaussian Indicators ( $\mu, \sigma, \tau)$ Across the Five Tasks

\begin{tabular}{|c|c|c|c|c|c|c|c|c|c|c|c|c|c|c|c|c|c|c|}
\hline \multirow[b]{2}{*}{ DV } & \multicolumn{6}{|c|}{ Medicated } & \multicolumn{6}{|c|}{ Placebo } & \multicolumn{6}{|c|}{ Parametric tests } \\
\hline & \multicolumn{3}{|c|}{ No incentive } & \multicolumn{3}{|c|}{ Incentive } & \multicolumn{3}{|c|}{ No incentive } & \multicolumn{3}{|c|}{ Incentive } & \multirow{2}{*}{ df } & \multirow{2}{*}{$\begin{array}{l}\text { Med } \\
F(E S)\end{array}$} & \multirow{2}{*}{$\begin{array}{c}\text { Incentive } \\
\text { F (ES) }\end{array}$} & \multirow{2}{*}{$\begin{array}{l}\text { ER } \\
F\end{array}$} & \multirow{2}{*}{$\begin{array}{c}\text { Med } \times \text { Incentive } \\
\text { F }\end{array}$} & \multirow{2}{*}{$\begin{array}{c}\text { Med } \times \text { ER } \\
F\end{array}$} \\
\hline Task & $1.5 \mathrm{~s}$ & $3.5 \mathrm{~s}$ & $5.5 \mathrm{~s}$ & $1.5 \mathrm{~s}$ & $3.5 \mathrm{~s}$ & $5.5 \mathrm{~s}$ & $1.5 \mathrm{~s}$ & $3.5 \mathrm{~s}$ & $5.5 \mathrm{~s}$ & $1.5 \mathrm{~s}$ & $3.5 \mathrm{~s}$ & $5.5 \mathrm{~s}$ & & & & & & \\
\hline \multicolumn{19}{|l|}{$\mathrm{Mu}$} \\
\hline Choice & $454.0(21.2)$ & $648.2(35.8)$ & $781.9(63.4)$ & $483.5(16.2)$ & $654.6(34.2)$ & $772.8(66.1)$ & $516.3(19.9)$ & $689.4(35.4)$ & $740.8(62.9)$ & $511.0(16.1)$ & $693.0(33.8)$ & $727.4(65.5)$ & 85 & $0.07(0.08)$ & $0.31(0.09)$ & $48.57 * * *$ & 1.03 & 0.96 \\
\hline ANT & $494.6(19.1)$ & $529.4(24.9)$ & $582.6(28.9)$ & $481.0(14.1)$ & $525.8(25.5)$ & $570.4(27.0)$ & $505.9(19.0)$ & $564.5(24.8)$ & $598.1(28.9)$ & $521.8(14.1)$ & $523.7(24.5)$ & $592.1(26.9)$ & 84 & $0.63(0.17)$ & $0.93(0.15)$ & 15.47**** & 0.10 & 0.67 \\
\hline GNG & $330.9(25.8)$ & $498.1(36.5)$ & $546.7(28.8)$ & $358.9(14.3)$ & $500.6(28.2)$ & $552.3(30.9)$ & $370.0(26.3)$ & $514.1(37.5)$ & $502.5(31.3)$ & $303.9(14.6)$ & $454.1(28.7)$ & $489.3(31.6)$ & 84 & $1.65(0.28)$ & $1.42(0.18)$ & $53.92 * * *$ & $6.23 *$ & 0.57 \\
\hline SST & $329.1(25.4)$ & $499.2(36.3)$ & $545.4(30.5)$ & $368.7(15.8)$ & $500.5(27.8)$ & $554.3(30.8)$ & 375.1 (26.4) & $525.6(37.5)$ & $527.1(32.2)$ & $307.5(15.9)$ & $460.9(28.1)$ & $498.4(31.4)$ & 88 & $0.72(0.18)$ & $1.29(0.17)$ & $52.88 * * *$ & $8.67 *$ & 0.32 \\
\hline N-back & $331.7(27.7)$ & $517.7(40.6)$ & $560.4(33.7)$ & $376.0(17.6)$ & $504.0(29.5)$ & $568.2(33.1)$ & $366.0(27.6)$ & $518.7(40.6)$ & $525.1(35.0)$ & $309.7(17.3)$ & $455.3(29.0)$ & $490.0(33.1)$ & 75 & $1.46(0.26)$ & $0.90(0.16)$ & $42.96 * * *$ & $6.44 *$ & 0.53 \\
\hline \multicolumn{19}{|l|}{ Sigma } \\
\hline Choice & $93.7(9.9)$ & $122.3(18.3)$ & $141.5(17.9)$ & $104.5(6.5)$ & | $18.7(14.7)$ & $130.6(17.2)$ & $125.2(9.2)$ & $167.9(18.1)$ & $160.2(17.8)$ & $124.5(6.4)$ & $147.1(14.5)$ & $141.1(16.9)$ & 85 & $3.00(0.37)$ & $0.27(0.08)$ & $4.35 *$ & 1.13 & 0.89 \\
\hline ANT & $93.7(8.1)$ & $88.4(11.2)$ & $77.0(9.4)$ & $83.8(5.5)$ & $79.4(9.0)$ & $78.3(9.8)$ & $124.3(8.1)$ & $122.6(11.4)$ & | $13.8(9.6)$ & $102.7(5.6)$ & $86.7(8.7)$ & $102.9(10.0)$ & 84 & $8.97 *(0.64)$ & $13.57 * *(0.57)$ & 2.02 & 3.56 & 0.61 \\
\hline GNG & $66.7(14.8)$ & $113.0(21.7)$ & $108.6(16.1)$ & $72.7(8.8)$ & $106.2(13.1)$ & | 14.1 (13.5) & $132.8(15.2)$ & $138.5(22.3)$ & $122.8(17.4)$ & $89.7(9.0)$ & $99.7(13.2)$ & $90.8(13.8)$ & 84 & $1.62(0.27)$ & $4.92(0.34)$ & 3.73 & 7.42* & 3.00 \\
\hline SST & $69.5(14.5)$ & | $12.8(21.3)$ & $1 \mid 3.0(16.1)$ & $75.6(9.1)$ & $105.4(12.9)$ & | 14.4 (13.4) & $134.1(15.1)$ & $143.1(21.9)$ & $128.8(16.9)$ & $91.1(9.1)$ & $103.5(13.0)$ & $93.9(13.7)$ & 88 & $2.01(0.30)$ & $5.97 *(0.37)$ & 3.72 & $7.45 *$ & 2.65 \\
\hline N-back & $72.4(15.9)$ & I24.I (24.1) & $111.5(18.1)$ & $77.3(10.0)$ & $99.2(13.2)$ & $119.6(14.8)$ & $128.5(15.9)$ & $144.9(24.1)$ & $122.6(18.7)$ & $92.1(9.9)$ & $101.8(12.8)$ & $90.1(14.9)$ & 75 & $1.46(0.26)$ & $4.18(0.33)$ & 2.28 & 5.19 & 2.69 \\
\hline \multicolumn{19}{|l|}{ Tau } \\
\hline Choice & $96.9(9.0)$ & 262.1 & $342.0(31.2)$ & $84.7(6.0)$ & $241.7(20.6)$ & 318.4 (35.8) & $69.4(8.2)$ & 286.8 & $360.3(31.0)$ & $78.4(6.0)$ & $274.7(20.4)$ & $386.8(35.2)$ & 85 & $0.88(0.20)$ & $0.35(0.09)$ & 1 1 $5.34 * * *$ & 3.40 & 1.82 \\
\hline ANT & $51.7(7.8)$ & $167.8(17.2)$ & $223.2(26.1)$ & $67.5(4.0)$ & $163.4(17.1)$ & $219.5(28.1)$ & $52.6(7.8)$ & $264.0(17.0)$ & $353.2(25.2)$ & $56.4(4.1)$ & $249.2(13.7)$ & $320.7(25.9)$ & 84 & $19.66 * * *(0.95)$ & $0.95(0.15)$ & $121.07 * * *$ & 1.70 & $11.03 * * *$ \\
\hline GNG & $153.5(17.0)$ & 246.1 (24.4) & 341.1 (30.2) & $133.8(9.7)$ & $251.3(26.5)$ & $302.0(34.6)$ & $197.5(17.5)$ & $348.7(25.1)$ & $428.9(32.0)$ & $185.8(9.9)$ & $326.2(26.8)$ & $392.9(35.4)$ & 84 & $9.29 *(0.65)$ & $2.77(0.26)$ & $66.18 * * *$ & 0.03 & 0.87 \\
\hline SST & $154.8(16.9)$ & 254.1 & $354.5(34.6)$ & $132.6(9.6)$ & $256.5(28.5)$ & $311.0(37.2)$ & $201.5(17.7)$ & $359.3(27.0)$ & $444.7(35.7)$ & $190.6(9.7)$ & $344.6(28.7)$ & $410.4(37.6)$ & 88 & $8.87 *(0.64)$ & $2.62(0.24)$ & $56.47 * * *$ & 0.02 & 0.95 \\
\hline N-back & $151.6(18.7)$ & 254.4 & $342.6(34.0)$ & $127.8(10.2)$ & $243.4(31.1)$ & $291.4(40.9)$ & $213.8(18.7)$ & $359.9(29.4)$ & $431.8(34.5)$ & $185.3(10.1)$ & $347.3(30.5)$ & $421.0(40.8)$ & 75 & $7.91 *(0.60)$ & $4.73(0.36)$ & $48.78 * * *$ & 0.01 & 0.66 \\
\hline
\end{tabular}

Abbreviations: ANT, Child Attentional Network Test; Choice, Choice Discrimination Task; DV, dependent variable; ER, event rate; ES, effect size (Cohen's d); GNG, Go/No-Go Task; SST, Stop Signal Task.

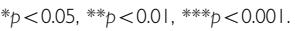


not affected by incentive condition. However, children in the placebo condition had significantly higher rates of accuracy in the incentive condition compared with the noincentive condition. No other interactions were significant across tasks. See Table 3.

\section{Other Performance Indicators}

There were no main effects of $\mathrm{MPH}(\mathrm{F}(1,88)=0.49$, $p=0.49)$ or incentive $(\mathrm{F}(1,88)=1.35, p=0.25)$ on the SSRT indicator from the SST. There was a main effect of ER $(\mathrm{F}(2,88)=47.40, p<0.0001)$, indicating that SSRT was longer as ER slowed. No interactions were significant (all $p$-values $>0.05$ ).

For the Alerting, Orienting, and Conflict indicators from the ANT task, there were no MPH or incentive main effects (all $p$-values $>0.05$ ). There was a main effect for ER on the Alerting $(\mathrm{F}(2,84)=51.35, p<0.0001)$ and Conflict scores $(\mathrm{F}(2,84)=9.38, p<0.001)$, indicating that children demonstrated less benefit from cueing and congruent flankers as ER became faster. The only interaction that reached statistical significance on the ANT indicators was an $\mathrm{MPH} \times \mathrm{ER}$ interaction on the Alerting indicator $(\mathrm{F}(2$, $84)=4.98, p<0.01)$. Children in the placebo condition demonstrated less benefit from cueing (ie, lower alerting scores) at fast ER and more benefit from cueing (ie, higher alerting scores) at slow ERs compared with children in the MPH condition.

\section{DISCUSSION}

The effect of stimulant medications on reducing RT variability in patients with ADHD was evident across multiple cognitive tasks. MPH attenuated RT variability across four tasks, which required a range of cognitive abilities (eg, attentional conflict, response inhibition, and working memory). However, on a simple choice discrimination task, stimulant medication did not reduce RT variability. These effects of MPH on RT variability were detected using a range of indicators (ie, RT SD, CV, and $\tau$ ). Although both RT SD and ex-Gaussian $\tau$ had comparable and moderate reliabilities, and intercorrelations between these indicators were generally quite high, the ex-Gaussian $\tau$ indicator most reliably detected effects of MPH on RT variability. This suggests that the component of variability affected by MPH is reduction of periodic-long RTs or positive distributional skew. The effects of MPH on task performance were largely specific to RT variability in this study, as MPH did not affect RT speed on any task, and only improved performance accuracy on two of the five tasks (ie, ANT and GNG).

Our primary MPH manipulation was achieved by determining each child's optimal dosage using a double blind, placebo-controlled crossover trial of $\mathrm{MPH}$, and then randomizing children to either receive their optimal dosage or placebo. Our study's titration methods produced very similar outcomes to the titration outcomes reported in the Multimodal Treatment Study of Children with ADHD (MTA; Greenhill et al, 2001) which used a similar, though more intensive daily dose titration schedule and methodology. Namely, the two studies had similar rates of stimulant response $(77 \%$ of children in our study $v s 77 \%$ of children in MTA), ultimate $\mathrm{mg} / \mathrm{kg}$ per day $(1.13 \mathrm{mg} / \mathrm{kg}$ in our study vs $0.8-1.15 \mathrm{mg} / \mathrm{kg}$ in MTA), and MPH vs placebo effect sizes on parent ( 0.82 in our study $v s 0.57$ in MTA), and teacher ( 0.87 in our study $v s 1.00$ in MTA) ratings of behavior. The effect sizes for MPH effects on RT variability in our study were in the moderate to high range $(0.60-0.95$ on $\tau$ ), which is fairly consistent with the MPH effect sizes for RT variability estimates of other studies using comparable tasks (Boonstra et al, 2005; Epstein et al, 2006). Of note, the effect sizes for MPH effects on RT variability are of similar magnitude as effect sizes reporting differences between ADHD and typically developing controls on RT variability (Klein et al, 2006), though some studies have reported between-group effect sizes beyond this range (de Zeeuw et al, 2008). A comparable set of effect sizes for betweengroup comparisons and medication effects suggest that MPH may normalize group differences on RT variability. Such normalization would imply that RT variability, as an indicator of brain function, is highly related to the pharmacodynamic mechanisms by which $\mathrm{MPH}$ exerts its effect in children with ADHD. Neuroimaging studies (Bellgrove et al, 2004; Weissman et al, 2006) and behavioral studies with brain-damaged populations (Dockree et al, 2006; Stuss et al, 2003; Stuss et al, 1999) have begun to isolate neurophysiological correlates of RT variability. Targeting regions of interest, which have been identified in this neuroscience literature, future research studies should focus on examining stimulant medication effects on brain function to better understand the mechanism of action by which stimulant medication produces robust effects on RT variability in children with ADHD.

Given the pervasiveness of MPH effects on RT variability, it is interesting to examine on which tasks and under which conditions MPH failed to attenuate RT variability. For one, we found no MPH effect on RT variability on the Choice task. This finding contradicts that of Spencer et al (2009) who used a very similar Choice Discrimination task as used in this study. Secondly, the MPH $\times$ ER interaction on the ANT (as measured by RT SD, CV and $\tau$ ) and SST (as measured by $\mathrm{CV}$ ) showed that MPH effects on RT variability were absent at fast ERs (ie, 1-s ISI). We believe that the source of both of these null findings is similar and can be attributed to our study's methodology. Spencer et al (2009) used a fixed 4-s ISI compared with our use of a range of ISIs (1-, 3-, and 5-s). Additional analyses of the choice data suggest that there was essentially no mean difference in $\mathrm{CV}$ between the MPH and placebo conditions at the fast ER (1-s ISI; ES $=0.01$ ), whereas during the long ER conditions, there were small- to medium-sized MPH effects (3-s ISI: $\mathrm{ES}=0.44 ; 5$-s ISI: $\mathrm{ES}=0.32$ ). We believe that the one-third of trials that used an ISI of 1-s likely masked the overall effect of MPH on RT variability. Although the effects of MPH might have been smaller on the Choice task than on the other tasks, it seems that an effects of MPH still exists under the appropriate conditions. The MPH $\times$ ER interaction effect on the ANT and SST task also supports this explanation. On these tasks, there was no effect of MPH on RT variability at fast RTs, but there were increasing differences between children in the MPH and placebo groups as ER slowed. Most studies that have found effects of $\mathrm{MPH}$ on RT variability have used an ER that ranged 
between 2 and 4 s (Castellanos et al, 2005; Groom et al, 2010; Spencer et al, 2009; Tannock et al, 1995). At fast ERs (eg, 1-s ISI), it is possible that RT distributions become truncated because of the smaller response window. Indeed, a large percentage of responses in the N-back task during the 3-s $(21.4 \%)$ and 5 -s $(31.0 \%)$ ISI conditions exceeded $1-s$ in length. This leads us to conclude that the lack of effects of MPH on RT variability on the simple Choice Discrimination task, as well as on faster ERs on the ANT task may be a result of truncated RTs. This artifact may have led to results that limited the breadth of effects of MPH on RT variability as well as the magnitude of these effects.

One of the goals of this study was to examine the moderating effect of task manipulations (ER and incentive) on our MPH manipulation across the various RT variability outcomes. The ER manipulation is especially interesting in relation to the competing predictions regarding $\mathrm{MPH} \times \mathrm{ER}$ interaction effects that are suggested by prevailing theoretical models of ADHD. The state regulation dysfunction (SRD) model suggests that short and long ERs cause overand underactivation in children, which detrimentally affects performance (see Sergeant and Sergeant, 2005 and van der Meere et al, 2005 for reviews). Alternatively, the delay aversion (DA) model suggests that task performance will deteriorate as delays (ie ERs) get longer (Sonuga-Barke et al, 1992). As outlined by Sonuga-Barke et al (2010), according to the SRD model, MPH alters activation in patients and thus diminishes the detrimental effects of long ERs on neuropsychological performance but exacerbates performance during short ERs because of overactivation. In contrast, the DA model hypothesizes that MPH affects motivational context and increases the application of effort, and therefore attenuates the detrimental effects of longer ERs in a linear fashion. The point of difference between these two models is what occurs when children on MPH experience fast ER conditions. In the DA model, MPH does not detrimentally affect performance during short ERs. In the SRD model, performance is detrimentally affected during short ERs because of overactivation. We found that MPH did interact with ER on RT variability indicators on two of the tasks (ie, ANT and SST). The interaction showed that children taking MPH were not as affected by slower ERs as children on placebo. Also, during the fast ER conditions, there was little difference between children on MPH compared with placebo. This pattern, although it appeared for only selected RT variability measures on two of the five tasks, is more consistent with the DA model. However, the SRD model's prediction of poorer performance during the fast ER condition is based upon the assumption that $\mathrm{MPH}$ combined with a fast ER produces overactivation. Our 1.5-s ER condition may have been out of the range of fast ERs to produce an overactivation effect. It is possible that a faster ER may have achieved this effect. Also, given that activation states may differ across individuals, studies may need to tailor ERs on an individual by individual basis to determine thresholds for overactivation (Sonuga-Barke et al, 2010).

This study also examined the moderating effects of incentive (ie, reward and response cost) on RT variability, as well as other performance outcomes. Although there was a main effect of incentive on some variables on some tasks, indicating an inconsistent and small effect of incentive on performance outcomes, there was relatively no interaction of incentive and MPH across outcomes across tasks. This is consistent with the previous literature examining MPH and incentive interactions (Groen et al, 2009; Groom et al, 2010) showing no synergistic effect of $\mathrm{MPH}$ and incentive on performance outcomes. Interestingly, MPH and incentive interactions that were observed in the current study tended to occur on more difficult tasks (ie, SST, GNG, N-back) and primarily for measures of RT speed (ie, $\mu$, RT mean). Examination of $\mathrm{MPH}$ by incentive interactions may be influenced by difficulty of task and the strength of each manipulation such that incentives may not exert an additional influence if medication is producing maximal gains or if the task is relatively easy. The current study used an optimal medication dosage, which may have reduced the opportunity for incentives to improve performance as medication already reduced RT variability substantially.

It is also important to consider the nature of the incentive manipulation, which varies greatly across studies that have examined the impact of motivation on performance in children with ADHD. The current study used a counterbalanced block design to compare performance with and without incentives, consisting of reward and response cost, and children earned a material reward (eg, toys, games), although trial-wise feedback was not provided. The counterbalanced block design and material reward are strengths of this study compared with those using a fixed block order (eg, Uebel et al, 2010), which confounds the incentive condition and time on task, and studies that did not offer a material reward (eg, Slusarek et al, 2001). However, completion of the incentive and no-incentive conditions sequentially may have influenced the results such that children generally associated their performance on the task with obtaining a material reward at the end of the day, thereby reducing incentive effects. Although trial-wise feedback was not provided, which would have been a more powerful incentive manipulation, as children with ADHD are particularly sensitive to immediate reinforcement (eg, Sagvolden et al, 2005), studies reporting improved performance on cognitive tasks when incentives are provided in children with ADHD often do not include trial-wise feedback (eg, Groom et al, 2010; Stevens et al, 2002). In addition, Michel and colleagues (2005), did not find any performance differences on the SST during an immediate reinforcement condition (ie, point total accumulated on screen after each trial) compared with a delayed reinforcement condition (ie, points accumulated in the same way, but participants were not told of their points until the end). Findings such as this may occur because the actual material reward is delayed until the child completes the activity despite the presence of immediate performance feedback. In addition, incentives targeted response accuracy rather than speed or variability, possibly reducing incentive effects on RT variability. Interestingly, incentives improved response accuracy and speed on various tasks, suggesting that incentives influenced response speed despite the emphasis on accuracy. Finally, the inclusion of response cost may have reduced random responding when the participant is uncertain of the correct response, thereby increasing the number of omission errors.

Although the effects of MPH on RT variability were evident across multiple tasks and indicators, the effects of 
MPH on other performance indicators (ie, RT mean, accuracy) were few and inconsistent. Despite the fact that RT mean was highly correlated with RT variability indicators (eg, $\tau$ ), we observed no significant effects of MPH on RT speed across tasks despite the fact that other studies have found that MPH speeds RT (Epstein et al, 2006). In addition, MPH effects on accuracy were evident on only two of the tasks (ie, ANT and GNG). Moreover, there was no effect of MPH on SSRT, a commonly used indicator of response inhibition, which has been found previously to improve with medication (ie, get smaller) among children with ADHD (Tannock et al, 1989). On all these indicators, it is interesting that no significant effects were observed in this study, which in many ways used robust methodology compared with many previous studies, including a large sample, a titrated optimized dosing procedure, and a wide variety of RT tasks. A straightforward explanation of these results is that MPH primarily affects RT variability. However, it may be that the inclusion of task manipulations of ER and incentive introduced variance to the mean estimates and diminished our ability to detect MPH effects on these other outcome measures. Indeed, ER had very large effects across all performance indicators. However, the lack of any interaction effects between these manipulations and $\mathrm{MPH}$ argues against this explanation. Alternatively, it may be that introducing our within-task manipulations intrinsically altered the task characteristics enough to change the task demands and alter performance of task. For example, our ER manipulation may have inadvertently introduced a 'jittering effect,' similar to that produced by changing ER on a trial-by-trial basis, which has been shown to improve task performance in children with ADHD (Ryan et al, 2010). Such an effect may have improved performance in children across both groups and diminished our ability to find $\mathrm{MPH}$ effects.

There are limitations of this study which may have affected the results of the study. We have already noted some limitations of our incentive and ER manipulations. In addition to the noted limitation to the lower bound of our ER manipulation, our ER manipulation was also limited in terms of the upper bound. The 5.5-s upper bound may not have fully tested the interactive effects of MPH on ER, had slower rates been included. In addition, the MPH dosages used in this study also may have led to attenuated $\mathrm{MPH}$ effects. Although we used a placebo-controlled, double-blind titration trial to determine optimal dosage, the highest dosage used in the trial was $54 \mathrm{mg}$ for children $\geqslant 25 \mathrm{~kg}$ and $36 \mathrm{mg}$ for children $<25 \mathrm{~kg}$. Other studies (eg, Spencer et al, 2009) have used higher dosages. In our study, a considerable number of children received the highest dosage as their optimal dosage (ie, 24\%). Indeed, it could be that for some of these children, a higher dosage would have been optimal. Also, a significant minority of children $(24 \%)$ exited the titration trial, with the placebo dosage as their optimal dosage, which is comparable to stimulant response rate in other studies (eg, Greenhill et al, 2001). The fact that $19 \%$ of the children in the optimaldose condition received the same stimulant dosage (ie, placebo) as that received by the placebo-control group may have affected this study's ability to detect between group differences on some of the study outcomes (eg, accuracy).
In summary, RT variability, which appears to be one of the most ubiquitous and robust indicators of cognitive deficit in patients with ADHD (Castellanos and Tannock, 2002), appears to be significantly reduced by MPH. Moreover, this study's results suggest that MPH effects on neuropsychological tasks are largely specific to RT variability and also largest in magnitude on RT variability indicators. Our use of a medication-naïve sample helps in attributing observed effects of MPH to acute medication effects rather than cumulative and chronic effects of longterm MPH treatment (Andersen, 2005). Future research should examine how effects of MPH on RT variability relate to effects of MPH on ADHD behavioral outcomes. Behavior analog studies examining correspondences between RT variability and behavioral manifestations of attention (eg, Rapport et al, 2009), as well as neurophysiological studies examining neural patterns during periods of enhanced RT variability (eg, Bellgrove et al, 2004; Weissman et al, 2006) might help in elucidating the behavioral and neural correlates of RT variability and its response to $\mathrm{MPH}$.

\section{ACKNOWLEDGEMENTS}

Funding for this study was provided by $\mathrm{NIH}$ (R01MH074770). This research was also supported by a Mid-Career Investigator Award in Patient-Oriented Research (PI: Epstein; K24 MH064478) and two Mentored Patient-Oriented Research Career Development Awards from the National Institute of Mental Health (PIs: Brinkman \& Froehlich; K23 MH083881 \& K23 MH083027).

\section{DISCLOSURE}

Dr Epstein receives funding from Eli Lilly and Company as an investigative site for a pharmaceutical trial. Eli Lilly and Company market atomoxetine, a drug used to treat ADHD. The authors declare no other conflict of interest.

\section{REFERENCES}

Andersen SL (2005). Stimulants and the developing brain. Trends Pharmacol Sci 26: 237-243.

Bellgrove MA, Hester R, Garavan H (2004). The functional neuroanatomical correlates of response variability: evidence from a response inhibition task. Neuropsychologia 42: 1910-1916.

Benjamini Y, Hochberg Y (1995). Controlling the false discovery rate: a practical and powerful approach to multiple testing. $J R$ Stat Soc Series B Stat Methodol 57: 298-300.

Boonstra AM, Kooij JJ, Oosterlaan J, Sergeant JA, Buitelaar JK (2005). Does methylphenidate improve inhibition and other cognitive abilities in adults with childhood-onset ADHD? J Clin Exp Neuropsychol 27: 278-298.

Castellanos FX, Sonuga-Barke EJ, Scheres A, Di Martino A, Hyde C, Walters JR et al (2005). Varieties of attention-deficit/ hyperactivity disorder-related intra-individual variability. Biol Psychiatry 57: 1416-1423.

Castellanos FX, Tannock R (2002). Neuroscience of attentiondeficit/hyperactivity disorder: the search for endophenotypes. Nat Rev Neurosci 3: 617-628.

de Zeeuw P, Aarnoudse-Moens C, Bijlhout J, Konig C, Post Uiterweer A, Papanikolau A et al (2008). Inhibitory performance, response speed, intraindividual variability, and response 
accuracy in ADHD. J Am Acad Child Adolesc Psychiatry 47: 808-816.

Dockree PM, Bellgrove MA, O'Keefe FM, Moloney P, Aimola L, Carton $S$ et al (2006). Sustained attention in traumatic brain injury and health controls: enhanced sensitivity with dual-task load. Exp Brain Res 168: 218-229.

Epstein JN, Conners CK, Hervey AS, Tonev ST, Arnold LE, Abikoff $\mathrm{HB}$ et al (2006). Assessing medication effects in the MTA study using neuropsychological outcomes. J Child Psychol Psychiatry 47: 446-456.

Epstein JN, Langberg JM, Rosen PJ, Graham A, Narad ME, Antonini TN et al. Evidence for higher reaction time variability for children with ADHD on a range of cognitive tasks including reward and event rate manipulations. Neuropsychol (in press).

Fitzpatrick PA, Klorman R, Brumaghim JT, Borgstedt AD (1992). Effects of sustained-release and standard preparation of methylphenidate on attention deficit disorder. J Am Acad Child Adolesc Psychiatry 31: 226-234.

Greenhill LL, Swanson JM, Vitiello B, Davies M, Clevenger W, $\mathrm{Wu} \mathrm{M}$ et al (2001). Impairment and deportment responses to different methylphenidate doses in children with ADHD: the MTA titration trial. J Am Acad Child Adolesc Psychiatry 40: $180-187$

Groen Y, Mulder LJM, Wijers AA, Minderaa R, Althaus M (2009). Methylphenidate improves diminished error and feedback sensitivity in ADHD: an evoked heart rate analysis. Biol Psychol 82: $45-53$.

Groom MJ, Scerif G, Liddle PF, Batty MJ, Liddle EB, Roberts KL et al (2010). Effects of motivation and medication on electrophysiological markers of response inhibition in children with attention-deficit/hyperactivity disorder. Biol Psychiatry 67: 624-631.

Heathcote A (1996). RTSYS: a DOS application for the analysis of reaction time data. Behav Res Methods Instrum Comput 28: 427-445.

Hervey A, Epstein JN, Curry JF, Tonev S, Arnold LE, Conners CK et al (2006). Reaction time distribution analysis of neuropsychological performance in an ADHD sample. Child Neuropsychol 12: $125-140$.

Johnson KA, Barry E, Bellgrove MA, Cox M, Kelly SP, Daibhis A et al (2008). Dissociation in response to methylphenidate on response variability in a group of medication naive children with ADHD. Neuropsychologia 26: 1532-1541.

Johnson KA, Kelly SP, Bellgrove MA, Barry E, Cox M, Gill M et al (2007). Response variability in attention deficit hyperactivity disorder: evidence for neuropsychological heterogeneity. Neuropsychologia 45: 630-638.

Klein C, Wendling K, Huettner P, Ruder H, Peper M, Klein C et al (2006). Intra-subject variability in attention-deficit hyperactivity disorder. Biol Psychiatry 60: 1088-1097.

Krusch DA, Klorman R, Brumaghim JT, Fitzpatrick PA, Borgstedt AD, Strauss J (1996). Methylphenidate slows reactions of children with attention deficit disorder during and after error. J Abnorm Child Psychol 24: 633-650.

Kuntsi J, Oosterlaan J, Stevenson J, Kuntsi J, Oosterlaan J, Stevenson J (2001). Psychological mechanisms in hyperactivity: I. Response inhibition deficit, working memory impairment, delay aversion, or something else? J Child Psychol Psychiatry 42: 199-210.

Leth-Steensen C, Elbaz ZK, Douglas VI (2000). Mean response times, variability, and skew in the responding of ADHD children: a response time distributional approach. Acta Psychol 104: 167-190.

Logan GD (1994). On the ability to inhibit thought and action: a users' guide to the stop signal paradigm. In: Dagenbach D, Carr TH (eds). Inhibitory Processes in Attention, Memory, and Language. Academic Press: San Diego. pp 189-239.
Luce RD (1986). Response Times: Their Role in Inferring Elementary Mental Organization. Oxford University Press: New York.

Michel JA, Kerns KA, Mateer CA (2005). The effect of reinforcement variables on inhibition in children with ADHD. Child Neuropsychol 11: 295-302.

MTA Cooperative Group (1999). A 14-month randomized clinical trial of treatment strategies for attention-deficit/hyperactivity disorder. Arch Gen Psychiatry 56: 1073-1086.

Mullins C, Bellgrove MA, Gill M, Robertson IH (2005). Variability in time reproduction: difference in ADHD Combined and Inattentive subtypes. J Am Acad Child Adolesc Psychiatry 44: 169-176.

Pelham WE (1993). Pharmacotherapy of children with attention-deficit hyperactivity disorder. School Psych Rev 22: 199-227.

Rapport MD, Kofler MJ, Alderson RM, Timko TM, DuPaul GJ (2009). Variability of attention processes in ADHD: observations from the classroom. J Atten Disord 12: 563-573.

Rosa-Neto P, Lou HC, Cumming P, Pryds O, Karrebaek H, Lunding $\mathrm{J}$ et al (2005). Methylphenidate-evoked changes in striatal dopamine correlate with inattention and impulsivity in adolescents with attention deficit hyperactivity disorder. Neuroimage 25: 868-876.

Rubia K, Taylor E, Smith AB, Oksanen H, Overmeyer S, Newman S (2001). Neuropsychological analyses of impulsiveness in childhood hyperactivity. Br J Psychiatry 179: 138-143.

Rueda MR, Fan J, McCandliss BD, Halparin JD, Gruber DB, Lercari LP et al (2004). Development of attentional networks in childhood. Neuropsychologia 42: 1029-1040.

Ryan M, Martin R, Denckla MB, Mostofsky SH, Mahone EM (2010). Interstimulus jitter facilitates response control in children with ADHD. J Int Neuropsychol Soc 16: 388-393.

Sagvolden T, Johansen EB, Aase H, Russell VA, Sagvolden T, Johansen EB et al (2005). A dynamic developmental theory of attention-deficit/hyperactivity disorder (ADHD) predominantly hyperactive/impulsive and combined subtypes. Behav Brain Sci 28: 397-419.

Schachar R, Tannock R, Marriott M, Logan G (1995). Deficient inhibitory control in attention deficit hyperactivity disorder. J Abnorm Child Psychol 23: 411-437.

Sergeant JA (2005). Modeling attention-deficit/hyperactivity disorder: a critical appraisal of the cognitive-energetic model. Biol Psychiatry 57: 1248-1255.

Shaffer D, Fisher P, Lucas CP, Dulcan MK, Schwab-Stone ME (2000). NIMH diagnostic interview schedule for children version IV (NIMH DISC-IV): description, differences from previous versions, and reliability of some common diagnoses. J Am Acad Child Adolesc Psychiatry 39: 28-38.

Shanahan MA, Pennington BF, Willcutt EF (2008). Do motivational incentives reduce inhibition deficits in ADHD? Dev Neuropsychol 33: $137-159$.

Slusarek M, Velling S, Bunk D, Eggers C (2001). Motivational effects on inhibitory control in children with ADHD. J Am Acad Child Adolesc Psychiatry 40: 355-363.

Sonuga-Barke EJ, Taylor E, Sembi S, Smith J (1992). Hyperactivity and delay aversion-I. The effect of delay on choice. $J$ Child Psychol Psychiatry 33: 387-398.

Sonuga-Barke EJS, Wiersema JR, van der Meere JJ, Roeyers H (2010). Context-dependent dynamic processes in attention deficit/hyperactivity disorder: differentiating common and unique effects of state regualtion deficits and delay aversion. Neuropsychol Rev 20: 86-102.

Spencer SV, Hawk Jr LW, Richards JB, Shiels K, Pelham W, Waxmonsky J (2009). Stimulant treatment reduces lapses in attention among children with ADHD: the effects of methylphenidate on intra-individual response time distributions. J Abnorm Child Psychol 37: 805-816. 
Stevens J, Quittner AL, Zuckerman JB, Moore S (2002). Behavioral inhibition, self-regulation of motivation, and working memory in children with attention deficit hyperactivity disorder. Dev Neuropsychol 21: 117-139.

Stuss DT, Murphy KR, Binns MA, Alexander MP (2003). Staying on the job: the frontal lobes control individual performance variability. Brain 126: 2363-2380.

Stuss DT, Toth JP, Franchi D, Alexander MP, Tipper S, Craik FI (1999). Dissociation of attentional processes in patients with focal frontal and posterior lesions. Neuropsychologia 37: 1005-1027.

Tannock R, Schachar R, Logan G (1995). Methylphenidate and cognitive flexibility: dissociated dose effects in hyperactive children. J Abnorm Child Psychol 23: 235-266.

Tannock R, Schachar RJ, Carr RP, Chajczyk D, Logan GD (1989). Effects of methylphenidate on inhibitory control in hyperactive children. J Abnorm Child Psychol 17: 473-491.

Teicher MH, Lowen SB, Polcari A, Foley M, McGreenery CE (2004). Novel strategy for the analysis of CPT data provides new insight into the effects of methylphenidate on attentional states in children with ADHD. J Child Adolesc Psychopharmacol 14: 219-232.

Tucha O, Prell S, Mecklinger L, Bormann-Kischkel C, Kubber S, Linder $\mathrm{M}$ et al (2006). Effects of methylphenidate of multiple components of attention in children with attention deficit hyperactivity disorder. Psychopharmacology (Berl): 185: 315-326.

Uebel H, Albrecht B, Asherson P, Borger NA, Butler L, Chen W et al (2010). Performance variability, impulsivity errors and the impact of incentives as gender-independent endophenotypes for ADHD. J Child Psychol Psychiatry 51: 210-218.

van der Meere J, Marzocchi GM, De Meo T (2005). Response inhibition and attention deficit hyperactivity disorder with and without oppositional defiant disorder screened from a community sample. Dev Neuropsychol 28: 459-472.

Vaurio RG, Simmonds DJ, Mostofsky SH, Vaurio RG, Simmonds DJ, Mostofsky SH (2009). Increased intra-individual reaction time variability in attention-deficit/hyperactivity disorder across response inhibition tasks with different cognitive demands. Neuropsychologia 47: 2389-2396.

Weissman DH, Roberts KC, Visscher KM, Woldorff MG (2006). The neural bases of momentary lapses of attention. Nat Neurosci 9: 971-978.

Wolraich ML, Feurer ID, Hannah JN, Baumgaertel A, Pinnock TY (1998). Obtaining systematic teacher reports of disruptive behavior disorders utilizing DSM-IV. J Abnorm Child Psychol 26: $141-152$. 